\title{
Narrativa española contemporánea ${ }^{1}$
}

\author{
RoDRIgo RuBIo
}

Tengo que decir, antes que nada, que esta conferencia ha nacido de varias notas y artículos que yo empecé a dar -incluso de charlas con un breve guión - hace unos años, cuando terminaba la década de los sesenta y se iniciaba la de los setenta. Estábamos entonces en pleno «boom» de la narrativa latinoamericana, y aquí, entre nosotros, apenas si, literariamente, se hablaba de otra cosa. Había aparecido Gabriel García Márquez, se consolidaba Mario Vargas Llosa, se descubría a Guillermo Cabrera Infante, a Carlos Fuente, a Manuel Scorza y, de paso, se recordaba a escritores ya veteranos, como Juan Rulfo, Alejo Carpentier, Ernesto Sábato, Jorge Luis Borges, Eduardo Mallea, Lezama Lima y otros, poco antes totalmente ignorados o silenciados.

Por todo esto, los principales diarios y revistas del pais, en sus suplementos literarios, apenas si dejaban un huequecito para hablar de la novela española. $[\ldots]^{2}$

\section{LO NUEVO Y LO VIEJO}

Siempre, cada vez que ha asomado el aliento de una nueva generación, se habló con cierta dureza de lo viejo. Unas veces, las críticos; otras, los propios escritores. De una forma u otra, éstos y aquéllos querian poner como una señal o hito en el camino, marcando un linde o separación. Ninguna generación anterior ha podido eludir el golpe de la que ha venido a continuación. $Y$ podemos recordar las frases despectivas de

1. La presente conferencia fue pronunciada por el autor en el Colegio Universitario de Logroño el día 12 de febrero de 1975; con ella se inauguró un ciclo sobre "Literatura española contemporánea).

2. La aparición de corchetes indica la supresión de uno o varios párrafos del texto que, por razones de espacio $-\mathrm{y}$ con el permiso del autor-, hemos realizado. 
Valle-Inclán, respecto de Pérez Galdós, cuando el escritor canario era - sería y es- una de las plumas más grandes que ha dado España en todos los tiempos. Sin embargo, para los hijos suyos del 98 era «el garbancero». $\mathrm{Y}$ es que el mismo joven que menosprecia a sus padres, cambia de actitud respecto a sus abuelos. Suele ocurrir en la vida mismo, al margen de la literatura. Para los abuelos tiene un cariño menos apasionado, pero más lúcido. Pueden hablar de ellos con objetividad, sin dejar a un lado el tono amable y cariñoso. [...]

Quizá me equivoque si digo que algunos escritores de esa generación intermedia que aparece entre 1920 y 1936 - a la que Torrente Ballester llama «generación partida»- recobre algunos quilates más, por lo menos para los críticos. Y un caso claro es el de Ramón J. Sender, supervalorado en la actualidad, que es precisamente cuando peores novelas escribe, silenciándose durante algunos años sus libros La aventura equinoccial de Lope de Aguirre, Epitalamio del Prieto Trinidad y Requiem por un campesino español, que son obras verdaderamente geniales, superiores, incluso, a su famoso libro autobiográfico, Crónica del alba. Pero esto ha ido unido al «boom» de los hispanoamericanos. Escritores foráneos -aunque fueran de habla castellana, y escritores exiliados- han tenido últimamente mejor prensa que los autores españoles que han venido peleando, sin mucho eco y con regular lucimiento, desde los años cuarenta.

Quiero decir con todo esto que la generación víctima es aquélla que, nacida en nuestros duros años de postguerra, se encontró con un mundo difícil y con un compromiso nada pequeño frente a su horizonte. Esta generación, que procuraré estudiar aunque sea someramente, no ha hecho, al parecer, la novela que ahora muchos exigen. Prueba evidente de ello es que Torrente Ballester, uno de sus componentes, gana gloria ahora, cuando, escéptico, de vuelta ya de muchas cosas, escribe. sin importarle nada el resultado, un experimento novelesco que - hay que reconocerlole sale genial. Me refiero a La saga fuga de $J$. B. Sus libros anteriores apenas si habian sido comentados, y entre esos libros se encontraban los pertenecientes a la trilogía Los gozos y las sombras: El señor llega, Donde da la vuelta el aire y La Pascua triste, que son novelas formidables, aunque constreñidas más al realismo que por esos años — década de los cincuenta — se llevaba. El autor, sin embargo, es el mismo, y lo que de genial hemos visto en La saga fuga de J. B. estaba ya en la trilogía citada, incluso en Don Juan y Off-Side. Pero, por entonces, Torrente Ballester parecía un escritor oscuro, integrado en el vivir monótono del país, y después ha sido el hombre más escéptico y rebelde que ha huído de apoyos oficiales para refugiarse en su cátedra y escribir de la forma que ha creído más conveniente. Insisto que para mí, no por lo de ahora, sino por lo que hi- 
ciera siempre, es una de las ocho o diez piumas que pueden pasar, con todos los honores, entre los de su generación, a la historia de la literatura contemporánea.

Pero volviendo a esa generación de postguerra, conviene que sepamos si sus componentes podían irse hacia caminos de mero esteticismo o si, por el contrario, hechos de gran transcendencia impedían realizar todo aquello que hubiera supuesto un crecimiento en el arte narrativo. Es ahora cuando, para algunos, acomodados en un mundo que mira -o ha intentado mirar - de distinta manera, ven lo de otros años con poca admiración. Parece como si hubieran deseado que junto al desarrollo económico —crisis aparte- se produjera, a la vez, otra especie de desarrollo literario, con calidades más altas, con prosas más imaginativas y aladas, como si los que tuvieron que apechugar con los duros años de postguerra les hubieran quedado demasiadas horas libres para ejercitarse en malabarismos literarios, algo que ahora, por lo que se ve, muchos críticos hubiesen agradecido. Pero digamos que el caso de Alvaro Cunqueiro, dado a una literatura de sabor medieval y cien por cien imaginativa, tendría que ser cosa aislada, como en realidad ha sido. Dejando un poco al margen a Ana María Matute, con mundos propios y narraciones fuera de cualquier tiempo, la mayoría de los escritores de esa generación -Delibes, Aldecoa, Castillo-Puche, Tomás Salvador, Francisco Candel, Luis Romero, Castillo Navarro, Carmen Laforet, Elena Quiroga, Dolores Medio, etcétera- se han movido más por la parcela realista. Y los que les siguieron, como Ferlosio, Fernández Santos, López Salinas, Antonio Ferres, Juan y Luis Goytisolo, Juan Marsé, Ramón Nieto, Juan Garcia Hortelano, Isaac Montero, etc., aún hincaron más el aguijón en el realismo, dando a sus obras un tratamiento enteramente social, cuando no socializante. Quizá, como Ana María Matute, sólo Camilo José Cela, de entre los primeros y los segundos, escapa de un realismo de urgencia. La escritora, por la gran riqueza de su mundo interior; el escritor, porque siempre se ha movido entre el laboratorio literario y las herencias, que aprovechó bien, de autores anteriores, como textos del Siglo de Oro, obras de Valle-Inclán, Baroja y José Gutiérrez Solana.

En mayoría, todos los escritores de esas dos décadas - años cuarenta y cincuenta, y con los que asomaron en los sesenta- se han movido dentro de un realismo inevitable, pues unos y otros, por circunstancias sociopolíticas, se veían obligados a hacer crónica viva de su tiempo, desechando, como los franceses del «Nouveau roman»y los italianos del neorealismo, todo lo que tuviera semejanza con lo meramente novelesco. Son raros los escritores que se mueven en una corriente tradicional, caso de Zunzunegui, y pocos los que se inclinaban por la mera invención, caso de Cunqueiro. La novela española quiere ser nueva $y$ huye de lo deci- 
monónico. Afronta el realismo, y se queda a milad del terreno, porque circunstancias muy poderosas obligan a dejar en esbozos lo que pudieron ser novelas de más amplios vuelos y más honda penetración. Podríamos verlo estudiando la novelística de Castillo-Puche, de Francisco Candel, de López Pacheco, de tantos otros que ahora, posiblemente, sean ignorados $o$ infravalorados.

Pero cabe que esas circunstancias histórico-políticas no salven a nuestra novela realista, porque me dirán que además de realista ha sido pobre en cuanto a forma, estilos, lenguaje y, sobre todo, en esa especie de soplo que llamamos intelectualidad. Si salvamos algunas excepciones -Antonio Prieto, Fernández Santos, Carlos Rojas, Andrés Bosch-, pocos autores se inclinaron por escribir bien y además penetrando. Habíamos tenido como modelo la novelística que nació entre los años 1920 y 1930 . Sobre todo, en varios países europeos. Habíamos conocido la obra de un Aldous Huxley, de un Thomas Mann, de un Marcel Proust, de un André Gide, de un Hermann Hesse, de un Joyce y de un Kafka. Y esto, podemos preguntarnos, ¿no fue acicate para que nuestras plumas de los años cuarenta, y las que siguieron a éstas, emprendieran, siquiera de vez en cuando, un intento de novela con altura intelectual y reformadora?

A lo mejor, todo aquello, lo europeo, quedaba lejano entonces. No era ésta la generación europeísta del 98, ni tampoco la otra generación culta y esteticista, cuyo centro máximo radicaba en Ortega y sus teorías. Nos habiamos quedado solos, con aquellos fogosos europeístas en la ancianidad y con los cultos y modernos teóricos como sin fuerza en su pluma. Vivíamos nuestro momento histórico, que era el de una lucha y luego el de un pan escaso, que no daba energías, esa es la verdad, para leer a Joyce ni tampoco al triste y retorcido Kafka. Esto lo han hecho escritores que han llegado después, ya en nuestros años, y de ahí que lo que muchos llaman nuevo, novísimo y hasta experimental, tenga tanta huella de aquel viejo hacer de plumas europeas ya desaparecidas, con el mezcladillo que les han servido los nuevos narradores latinoamericanos. Pero vayamos despacio y observemos hechos de la historia.

\section{TIEMPO SIN VOZ}

Tiempo sin voz es aquél en el que empezaron a dar señales de vida unos escritores jóvenes que, lo reconozcamos o no, aparecían con una palabra nueva. Recogían una herencia con la que no era posible mantener ninguna conexión No había cuajado la novela cerrada, intelectual, que preconizara Ortega, y había quedado como suelta la deshilvanada y a la vez rica novela barojiana. Se nos habían quedado en humo, en nieblas suaves, las prosas impecables de Gabriel Miró. Habían dejado de interesar- 
nos las novelas de la última época de Blasco lbáñez, tan aventureras y cosmopolitas. Se habían quedado como bailando en su «Cuento semanal» una serie de escritores prolíficos pero sin gran transcendencia, como López de Haro, Alberto Insúa, Pedro Mata, Cijes Aparicio y otros. Concha Espina era la novelista que parecía interesar más, por lo menos a un determinado público, eufórico, de postguerra. Con ella, Wenceslao Fernández Flórez. Se diluía Ricardo León, el de las prosas almibaradas y barrocas. La obra de Baroja seguía, redondeándose con sus ácidos libros de memorias. Valle-Inclán, por otra parte, estaba como atado a su Ruedo Ibérico, un poco a sus Sonatas y otro tanto a la genial Tirano Banderas. Era, sin embargo, el autor de los esperpentos teatrales, que a muchos lectores de aquella época no gustaban, o gustaban muy poco. Prueba evidente de ello es que han tenido que pasar treinta años para que esa literatura teatral de Valle-Inclán haya alcanzado el éxito que sin duda merecía.

De los escritores que aparecen por entonces - años de postguerralos habrá barojianos, otros que rozarán un poquitín a Valle-Inclán y algún otro que se detendrá en las suaves prosas mironianas y azorinianas. Citaría, respecto a Baroja, a Zunzunegui, aunque él dice que, como novelista, prefiere a Galdós, y cabe que su obra tenga más influencias del autor canario que del vasco; en cuanto a Baroja, han sido muchos, además de Cela, los que lo han admirado y seguido. Sobre Miró y Azorín, fueron menos autores de nuestro tiempo los que se inclinaron. Uno, sin embargo, con cierta pasión: Pedro de Lorenzo. Todavía no se rompe con lo viejo y es aprovechable todo aquello que viene de generaciones anteriores. Las influencias externas no se notarán mucho todavía. Tendrán que aparecer escritores más jóvenes, ya atentos a lo que ocurre en Europa y en el mundo, para que esas influencias foráneas sean apreciables. Cuando aparezca Carmen Laforet, con su novela Nada, ya se hablará del existencialismo y sus influencias; cuando leamos libros de otras autoras, diremos que las hermanas Brontë, con sus relatos decimonónicos, y Catherine Masfield, y Daphne Du Maurier, ejercen su fuerza entre las plumas nuestras no muy sólidas. Cuando lleguen los escritores de los años cincuenta -con Ferlosio como pluma más destacada- ya no tendremos más remedio que hablar del objetivismo o el «nouveau roman» puesto de moda en Francia; cuando leamos novelas de Ferres, de López Salinas, López Pacheco, Juan y Luis Goytisolo, Juan Marsé y algún otro, nos diremos que, sin apenas advertirlo, nos hemos unido - aunque caminando detrásal neorrealismo italiano de postguerra, tan bien cultivado por Egli Vittorini, Vasco Pratolini, Claudio Bassani, Cesare Pavese y otros.

Sin embargo, podemos decir que aquel tiempo, en sus comienzos, y aquí entre nosotros, tenía poca voz. Porque las novelas de Ramón Gómez de la Serna eran algo aislado, como troupes de un circo inventado por él. 
Zamacois se perdía en la distancia, aunque famoso. Ledesma Miranda y otros de su tiempo parecían como condenados a guardar silencio, aunque tuvieran comentaristas elogiosos. Los que, con urgencia, escribieron las primeras novelas del conflicto bélico - como Agustín de Foxá, Rafael Borrás y hasta Wenceslao Fernández Flórez, sin olvidar a Concha Espina- tendrían, a la fuerza, una sola clase de público. Los llamados a mantener un hilo interrumpido entre los maestros del 98 [..] desaparecieron y quedaron poco menos como silenciados. Entre ellos, Ramón J. Sender, Arturo Barea, Serrano Poncela, Francisco Ayala, Rosa Chácel, Manuel Andújar, Merce Rododera - la escritora catalana posiblemente de más categoría, junto a Ana María Matute-y algunos más. Se produjo la ruptura, la desbandada, y de muchos de estos nombres apenas si hemos sabido nada en largos años, pues fueron dando sus originales a editoriales de Argentina y Méjico y aquellas repúblicas quedaban muy lejos para nosotros, bastante aislados en todos los órdenes.

Había llegado, para los que estaban aquí, un tiempo de destrucción y de reforma. Se tropezaba, además, con aquel inmenso vacío - falta de obra interesante- $-y$, además, conocíamos muy poco de las nuevas tendencias de la novela grande, intelectual, poderosa, que se había escrito y se seguía escribiendo en Europa y en el mundo. ¿Quién, como lector, hablaba de William Faulkner, de Teodoro Dreiser, de John Dos Passos, de Hemingway, de Scott Fitzgerald, de John Steinbeck, grandes escritores norteamericanos? ¿Quién leía a Marcel Proust, a Thomas Mann, a Joyce, a Kafka, a Robert Mussil, que eran piezas importantísimas en el quehacer literario de Europa? Nosotros estábamos acostumbrados a la novela con argumento, al relato de aventuras, en donde el lance, la acción, la peripecia, se alzan por encima de todo. Y luego, cuando ya se empezara a estudiar a esta primera generación de postguerra, críticos competentes como Leopoldo Rodríguez Alcalde y Juan Luis Alborg dirian que no, que la novela actual no podía ser eso. Estos críticos, por fortuna para la generación viviente, apoyaban el realismo y la profundidad temática. De ahí que, al hablar de la nueva novela española, nos citaran la narrativa más importante de otros países. Esto suponía, para el lector, y a la vez para el lector-escritor, una mirada a mundos más amplios. Fue ya por los años cincuenta cuando se nos hicieron familiares las tendencias narrativas de otras geografías, de ahí que hayan insistido en ellas, no los recién aparecidos en los años cuarenta, sino, por contra, los que podríamos considerar de la segunda generación.

Empezó entonces la valoración y a la vez la comparación. Pero antes, insisto, habíamos tenido escasa noticia de lo foráneo, pues cuando pudo dársele importancia a todo lo extraordinario del extranjero, aquí se recibía mal. Se aceptaban, sin embargo, una larga serie de escritores más 
bien de segunda fila, a los que se traducía profusamente. Leíamos a Daphne Du Maurier, a Sommerset Maugham, a Charles Morgan, a Cecil Roberts, a Maxence van der Meersch, a Pearl S. Buck y un poquito también - porque llegaban entre todos esos nombres_ a François Mauriac, a George Bernanos y a algún escritor norteamericano, como Hemingway, John P. Marquand y Louis Bromfield, que eran interesantes, pero no los mejores de aquel país.

¿Cómo empezar, pues? ¿Qué preocupaba entonces aquí? Existe una temática de urgencia: la guerra civil y los años de postguerra. Ningún escritor - o muy pocos-_ de la nueva generación, podrán eludir este compromiso. Esto es más fuerte que nada y podrá más que la voluntad de cada uno. Por eso, los que hicieron prosas de invención y en cierto modo evasivas, fueron muy pocos. No es una moda, creo yo, tocar una serie de temas. Es una necesidad. Y esto - lo sabemos- puede llevar pobreza a una literatura. Esto puede producir un realismo que, quizá pronto, quedará desgastado. Pero yo diría que para aquellos escritores, desde Cela a Concha Alós, pasando por múltiples plumas, no había otra salida. Algunos hicieron sus propios ejercicios evasivos, apoyándose en lo meramente literario - caso del citado Cela_, otros pudieron recrearse en la inventiva, más o menos transcendente —caso de Cunqueiro-. Pero el denominador somún de toda una amplia generación fue el realismo, sin magia ninguna.

El tema estaba aquí, y creo hubiera sido poco recomendable que nuestros escritores de los años cuarenta y cincuenta se hubiesen puesto entonces a hacer malabarismos de lenguaje, a realizar obras puramente novelescas; es decir, que hubiésemos tenido que censurarles el que no se comprometieran con su tiempo $\mathrm{y}$, por tanto, alejado de una narrativa que ellos, aunque no lo apreciemos, nos han dado. Yo creo que, hasta siendo pobre, esta narrativa ha de tener gran importancia por cuanto de testimonio hay en ella de la vida nuestra, de los años que hemos vivido. Si el Siglo de Oro, como afirmara en un ensayo Juan Goytisolo, puede conocerse mejor a través de textos literarios como La Celestina, El Lazarillo y otros libros de la picaresca, también cabe que los años de postguerra puedan estudiarse mejor, en un tiempo futuro, a través de la literatura -novela especialmente- que de los tratados de historia. Nosotros no teníamos grandes revistas o «magazines» donde publicar el reportaje realista de urgencia, como ocurría en otros países. De ahí que el escritor del momento se fuera directamente a la novela, convirtiéndola, muchas veces, en mero reportaje, por el afán de decir cosas del momento. Y podríamos colocar aquí novelas de Gironella, de Angel M. ${ }^{a}$ de Lera, de Castillo-Puche, de Francisco Candel, de Tomás Salvador, de Luis Romero, etc., salvándose, 
por llegar a una literatura de mayores calidades, Miguel Deliges, Ignacio Aldecoa, Antonio Prieto, Sánchez Ferlosio, Ana María Matute y alguna pluma más.

\section{REPORTAJE Y NOVELA TESTIMONIO}

Sé que, por todo eso, a muchos críticos les han sobrado motivos para calificar a nuestra novela de postguerra un tanto raquítica. Cierto que lo han dicho ya muy a última hora, cuando estábamos en pleno «boom» de la narrativa latinoamericana, cuando Ana María Matute - a la que sin duda en otro tiempo alguien consideró peligrosamente fuera del realismo actual, calificándola de subjetiva-, y cuando Torrente Ballester daba un giro brusco y nos salía con inventos y aventuras extraordinarias - las de $J$. B.-, y cuando Fernández Santos insistía en su decir con buen pulso y escasa transcendencia, y cuando algunos pocos insisían en lo de la novela intelectual - Manuel Garcia-Viñó, apoyándose en Vintila Horia, Carlos Rojas, Andrés Bosch y Antonio Prieto-, y cuando, al mismo tiempo, Alfonso Grosso se iba de su viejo realismo social a una novela barroca y colorista (Guarnición de silla y Florido mayo), y cuando, ya, se hablaba con insistencia de Juan Benet y sus novelas de apretada y abstracta prosa, y cuando la aparición de J. Leyva y sus novelas experimentales podrían dar la razón a unos comentaristas cansados de leer realismo, tenemos que reconocerlo, pero un tanto asombrados al ponerse delante libros como Cien años de soledad, de García Márquez; Paradiso, de Lezama Lima; El siglo de las luces, de Alejo Carpentier, y todo el complicado mundo imaginativo de Borges y Cortázar.

Por todo esto, ganaban enteros escritores que habían permanecido fieles a su forma subjetiva de hacer, caso de Ana María Matute, y los que siempre anduvieron por la invención, caso de Alvaro Cunqueiro, y como los que, desde el tremendismo realista, se pasaban a inventos jocosos, como Cela, y como escritores que, medio silenciados, se alzaban por una segunda sbra de pura invención - caso de Benet - hasta alcanzar categoría superior, según algunos comentaristas.

Quedaba desprestigiado el reportaje y muy malparada siempre toda la prosa realista. Menos mal que ensayos como los del profesor Pablo Gil Casado daban su importancia a la novelística social (sobre todo en la segunda edición de su libro publicado por Seix Barral) puesta en pie por los años cuarenta y cincuenta. Menos mal, también, que muchos lectores -y asimismo comentaristas- han apreciado en lo que valen obras de Candel - tan realista o poco dado a la inventiva siempre- y de Juan Marsé (el único que no se ofuscó con el objetivismo, cuando tanto lo apoyaba el teórico de la casa Barral, el crítico Castellet, y el único, tam- 
bién, que no ha tenido que dar giros bruscos para venir de un amaneramiento narrativo, aunque se le viera algo en Encerrados con un solo juguete, tan de moda todo lo referente a la náusea y al existencialismo entonces, para llegar, con mucha fuerza, a sus últimas novelas, realistas, pero poderosas, como Ultimas tardes con Teresa, La oscura historia de la prima Montse y la que ahora - algo disparatada- ha publicado en Méjico, Si te dicen que caí). Otros escritores de esa editorial, dado que se imponía ya el realismo mágico, la novela más subjetiva (por el impulso de los hispanoamericanos, tan barrocos muchos de ellos), se han apresurado a dar ese cambio brusco. Lo hemos visto en Juan García Hortelano, en Grosso, en Caballero Bonald. Otros escritores, que publican sus libros en editoriales menos vanguardistas, han seguido en su línea, realista y honrada, y aproximándose, como Tomás Salvador en sus últimas novelas, al mundo futurista, un tanto frío y científico, aunque muy eficaz.

También otros escritores, empeñados en dar vida a un nuevo realismo, han hecho intentos no siempre bien aceptados por el público que lee novelas. Entre éstos se encuentran los que ha apoyado en sus ensayos criticos Manuel García-Viñó, como Carlos Rojas - con Auio de fe- y Antonio Prieto, con Secretum.

Lo que quizá hemos olvidado siempre aquí es hacer la novela realista, pero en grande, de forma transcendente. Como han sido, por ejemplo, las novelas de John Steinbeck, Al este del Edén, Las uvas de la ira y otras. Y las novelas del también norteamericano Erskine Caldwell, desde La hacienda de Dios a La ruta del tabaco, pasando por La casa de la colina y sus enormes y extraordinarios cuentos. $\mathrm{Y}$ las novelas de John Dos Passos, tan imitadas por algunos en cuanto a su técnica objetiva y cinematográfica. Esta gran novela es la que no se ha hecho. Pero yo creo que los escritores españoles merecen una disculpa, a este respecto. Se ha podido, antes, escribir bien, con buena prosa, que escribir con apertura y profundidad. Algo ha frenado; algo extraliterario, quiero decir.

Por los primeros años sesenta, cuando yo aparecí como escritor, el realismo era ya -al menos para mi- un cansancio, pero todavía una necesidad. Ahora bien, confieso que no estaba conforme con las técnicas expositivas del realismo objetivista. Presentía que esa tendencia, como todo lo importado, tendría que debilitarse. A mí no me atraía en absoluto, y digo esto a modo de ilustrar mis ideas generales sobre la novela y sobre el realismo en particular. Valía el realismo, pero en más profundidad; valía lo social -a mi juicio-, pero no rebuscando los temas en suburbios, en escenarios exclusivamente pobres. La novela, cualquier novela, podría ser - y de hecho debía ser - un todo, un mundo, en el que cupiera lo bueno y lo malo. $Y$ en cuanto a formas, me agotaban los diá- 
logos reiterativos, las acotaciones, tan excesivamente literarias a veces. Por eso, desde que empecé, no quise ser ni tan literato como algunos, ni tan poco profundo como la mayoría. No me había interesado mucho el objetivismo, ni siquiera como lector, aunque me deleitara con $E l J a$ rama, libro que salvo de todos esos años y esas tendencias; no me habían atraído tampoco las novelas con intención de sociales, ancladas en suburbios, como muchas de Juan Goytisolo, y, sin embargo, me atrajo siempre el quehacer de Candel, por sincero y doloroso, por auténtico y vivo, y me gustaba, también, la rabia, el encono que Juan Marsé ponía en sus narraciones fuertes $\mathrm{y}$ bien trazadas. Me parecía que el realismo aún tendría que estar vigente, porque el escritor es o ha de ser siempre una persona comprometida con su tiempo, y debe dar testimonio de lo que sucede en su entorno. Lo que no me gustaba era el tratamiento, rebuscado, artificioso, de la mayoría de los libros que durante quince años se habían escrito. Se salvaba para mí, además de los escritores quue he nombrado hace unos momentos, Ana María Matute, con sus mundos propios, algo tétricos, pero poéticos a la vez; realistas en su enmarque, objetivos según en qué momentos y subjetivos y grandes siempre. No me importaba el que descubriera influencias de Faulkner en esta escritora. Faulkner ha sido uno de los escritores contemporáneos más poderosos del mundo y sus influencias llegaron a Europa, a España, lo mismo que se han extendido por toda Hispanoamérica, cayendo a veces, para medrar, en parcelas literarias que nos parecen tan originales y sólidas como la de Gabriel García Márquez. Lo inalo es cuando algunos de los influídos han llegado incluso a imitarle. Eso ya era un peligro, y de ahí que ciertos autores españoles, dos premios Nadal - y digo sus nombres: Alfonso Martín Garrido, autor de El miedo y la esperanza, y Ramiro Pinilla, que firmó Las ciegas hormigas, tan tremendamente faulknerianas una y otra novela-, tengan tantas dificultades para seguir adelante.

El aliento de Faulkner revitalizó la novelística en muchos puntos del mundo. Yo confieso que me interesó y de alguna manera me alentó para trazar mis prosas largas, como las de Equipaje... y La espera, que eran novelas realistas, duras, ciertamente amargas, pero alejadas ya del realismo social objetivo, del que tanto se había abusado.

De esta forma, a mi juicio, la novela podía tener mucho realismo, trazarse incluso como reportaje, e interesar. Los grandes novelistas rusos de hoy, igual que en otro tiempo Tolstoi y Dostoiewsky, vendrían a demostrárnoslo. [...]

Sin embargo, el propio escritor sabe cuándo debe evolucionar. Hay momentos que necesita transformar el realismo, o valerse de un realismo transformado - deformado- para decir verdades superiores. No es ne- 
cesario que recurra a influencias externas, cuando aquí hemos tenido a Cervantes, al autor del Lazarillo, a Valle-Inclán y, también, a Goya y Gutiérrez Solana (éste como escritor y como pintor). Las prosas de unos, la pintura dei sordo de Fuendetodos, pueden ser un apoyo y una referencia. La narrativa española ahora no tiene por qué ser realista; ahora bien, a mi juicio -y yo lo intento, sin éxito, por cuestiones de administración, entiéndase censura-, este realismo debe voluntariamente deformarse, buscando la caricatura y en ella los símbolos.

Cada momento nos dice qué tenemos y cómo tenemos que escribir. Los latinoamericanos, influencias faulknerianas aparte, no han hecho más que reflejar la tiranía y el caos en que viven ciertos pueblos de su hemisferio. Esto, en la distancia, puede manejarse bien, muy eficazmente, como ha hecho Vargas Llosa al escribir La ciudad y los perros y Conversación en la catedral. Estos son libros realistas, puesto que el autor no elude el compromiso de su tiempo y da testimonio de unas formas de vida polítincosociales y humanas. Pero deforma intencionadamente. Se vale del lenguaje, de las cadencias propias de unas formas expresivas locales para, así, reconstruir, a su manera, realidades que, de cualquier modo, quedan feroces, y es posible reflejarlas lejos de las trabas que le hubiera supuesto escribir y publicar este libro en su propio país.

Insisto, pues, en que de nuestro realismo podremos sacar mucho positivo, pese a los giros, casi obligados, que dio nuestra narrativa en los últimos años. No es despreciable todo lo que se ha hecho, y pensemos que, valorado este tiempo con una perspectiva mayor, veriamos que lo positivo es, posiblemente, más de lo que ahora suponemos. Y daré nombres que de alguna forma pueden quedar para el tiempo futuro.

\section{UN RECUENTO APRESURADO}

Ya, a lo largo de mi charla, he nombrado a los naradores más representativos de cada década. Pero voy a insistir en algunos nombres, a la vez que hablo de las tendencias imperantes en unos y otros años.

Si la creación novelística no se moviera sólo por unas altas esferas de mayor capacidad intelectual, a lo mejor sufriría continuos descalabros. $Y$ yo recuerdo a este respecto el empeño que puso Miguel Delibes, hace ya años - al comienzo de la década de los sesenta-, cuando se celebró un coloquio internacional en Formentor, defendiendo lo humano en la novela. Estaba todavía muy fuerte la corriente objetivista, el neorrealismo, y se abogaba por una novelística quizá -y sin quizá- más fría e intelectual. Tampoco, en otra época, don Pío Baroja estuvo de acuerdo con Ortega y Gasset, cuando el filósofo y ensayista abogaba por una nove- 
la cerrada, intelectual, influenciado, sin lugar a dudas, por las corrientes europeas de entonces, donde Marcel Proust había marcado hitos con La busca del tiempo perdido; Thomas Mann era el gran narrador de Alemania, autor de La montaña mágica; Robert Mussil era el novelista frío e intelectual de Austria; Joyce, el revolucionario irlandés que daba un giro radical en la forma de narrar, mientras los libros de Franz Kafka iban llegando a las élites minoritarias del intelectualismo.

Baroja se puso en contra de Ortega, y entre nosotros fue el narrador quien más acierto tuvo, puesto que los posibles seguidores de las teorías orteganianas nunca fueron más allá de ligeros experimentos novelísticos, y éstos, hechos más al aire del vivir ibérico que por la influencia intelectual externa. Porque entre esos novelistas, Ramón Gómez de la Serna, Gabriel Miró, Ramón Pérez de Ayala y Benjamín Jarnés, aunque con cierto intelectualismo, siguieron una andadura propia y no demasiado briosa como para marcar hitos y suscitar tendencias. Lo barojiano fue más poderoso, como después hemos visto por los seguidores de unos y de otro. $[\ldots]^{3}$

Lo más destacado, sin embargo, en el momento actual, es lo que han hecho escritores ya maduros, de la que podemos considerar primera generación de postguerra, como Torrente Ballester, al darnos La saga fuga de J. B., y Miguel Delibes, con La parábola del náufrago y El príncipe destronado.

Se consolidan autores poco conocidos, como Vicente Soto, residente en Londres y premio Nadal por su buena novela La zancada, mientras jóvenes aparecidos con cierto empuje, como Jesús Torbado, Juan Farias, Cela Trulock y hasta Umbral, se quedan en actividades periodísticas o de empresa que, por ahora, predominan en su quehacer literario.

\section{Punto Final}

Como seguir citando nombres siempre resultaria prolijo y hasta aburrido, dejándome, sin lugar a dudas, plumas que merecen un recuerdo -como la de Mario Lacruz, autor de La tarde y El ayudante del verdugo; como la de Mercedes Salisachs, con aciertos en algunas de sus primeras obras; como la del desaparecido Manuel Sanmartín, autor de El borrador; como la de Castillo Navarro, con tantos aciertos en sus primeras salidas-;

3. A continuación, el conferenciante se detiene en analizar la significación de la obra de autores como C. J. Cela, Delibes, Ana María Matute, Ignacio Aldecoa, Torrente Ballester, etc. El lector interesado en el tema hallará parte de lo aquí suprimido en la obra de Rodrigo Rubio Narrativa española, 1940-1970, Madrid, 1970. 
como una enumeración larga no es posible, voy a poner punto final, en un resumen con ciertas consideraciones.

Y digo, para esto, uniéndome a la voz de García Pavón (uno de los escritores que sin duda se hubiera merecido un buen párrafo), que la generación de postguerra - años cuarenta y cincuenta- fue, sin lugar a dudas, una «generación de robinsones». Escribía esto García Pavón a la muerte de Ignacio Aldecoa, glosando la obra de este buen narrador. Robinsones en una isla literaria árida y desierta. Robinsones en un mundo áspero y que prefería, para leer, los libros traducidos de Stephan Zweig, de Pearl S. Buck, de Somerset Maugham, de Daphne Du Maurier, de Chalotte Brontë, de Louis Bromfield y otros autores por entonces de moda. Estos escritores nuestros se propusieron hacer crónica de su tiempo, escribir como jóvenes y nuevos que eran, dejando a un lado los moldes decimonónicos. $Y$ como hemos visto $-y$ podemos ver aproximándonos a süs obras-, algunos han alcanzado categoría y son reconocidos más allá de nuestras fronteras, pues si bien es cierto que nunca se tradujeron demasiado a los escritores españoles, es ahora, por fortuna para nosotros, cuando más interés demuestran en otros países -y especialmente en los del Este- por conocer nuestra obra.

Algunos autores, aunque sean pocos, tienen la categoria de grandes narradores, y esto, tanto para los que escribimos obras de creación y somos compañeros suyos, como para los comentaristas y lectores en general, debe suponer un motivo de satisfacción.

Cierto que todo pudo ser diferente y tener ahora una novela mejor, más profunda, más lograda; pero no olvidemos en las circunstancias que nos hemos movido, y que factores extraliterarios, de orden administrativo, han influído, pesando como plomo sobre la pluma y el cerebro de todo creador. 
